patients for home blood glucose monitoring and that any who do not seem capable or are uninterested should not be shown the technique. Obviously you should teach patients carefully and not allow them to start unless you are sure that they are able to do the procedure properly.

H J BODANSKY

General Infirmary at Leeds,

Leeds LSI 3EX

1 Campbell LV, Ashwell SM, Borkman M, Chisholm DJ. White coat hyperglycaemia: disparity between diabetes clinic and coat hyperglycaemia: disparity between diabetes clinic and
home blood glucose concentrations. BMf 1992;305:1194-6. (14 November.)

EdrToR,-We agree with Lesley V Campbell and colleagues about the disparity between clinic and home blood glucose measurements in diabetes.' We reviewed 27 children who have attended our clinic recently and who undertake home blood glucose monitoring (we consider control to be good if $70 \%$ of measured concentrations are $<10 \mathrm{mmol} / \mathrm{l})$. We found that of the 15 patients with a fructosamine concentration in the range indicating good control $(<2.8 \mathrm{mmol} / \mathrm{l})$, nine had a clinic blood glucose concentration $>10 \mathrm{mmol} / \mathrm{l}$ (four having concentrations $>15 \mathrm{mmol} / \mathrm{l}$ ) and yet only two had evidence of less than good control in their home monitoring records. Of the 12 patients whose fructosamine concentration was in the range indicating fair control $(2 \cdot 8-3 \cdot 4 \mathrm{mmol} / \mathrm{l}), 10 \mathrm{had} \mathrm{a}$ clinic blood glucose concentration $>10 \mathrm{mmol} / 1$ (eight having concentrations $>15 \mathrm{mmol} / \mathrm{l}$ ) despite only seven having home monitoring records that indicated less than good control.

The authors point out that decisions can be difficult to make in the clinic if the glycated protein concentration at the time the patient is seen is not known. For the past two months such results have been provided for Southmead Hospital's children's diabetic service. The patients visit the clinical chemistry department for a fingerprick fructosamine test immediately before reporting to the outpatient department. By the time the patient has been weighed and measured the result has been telephoned over and is thus available when the patient is seen. The fructosamine concentration is measured in capillary serum samples with an in house nitroblue tetrazolium method standardised against deoxymorpholinofructose on a discrete analyser. This method is based on that described by Johnson et $a l^{2}{ }^{2}$ For patients seen at the various peripheral outpatient clinics the diabetic liaison health visitor takes the necessary blood sample a week before the clinic appointment, the result therefore being available when the patient visits the clinic.

The availability of this service has led to more useful consultations and removed the need to write to both the patient and the general practitioner after each visit. As this system has only recently been introduced, however, further evaluation will be needed.

$\begin{array}{rr}\text { CAROL SULLIVAN } & \text { TIMOTHY CHAMBERS } \\ \text { DAVID GOLDIE } & \text { MICHAEL GILLETT } \\ \text { ALISON WOODS }\end{array}$

Southmead Hospital, Bristol BS10 5NB

1 Campbell LV, Ashwell SM, Borkman M, Chisholm DJ. White coat hyperglycaemia: disparity between diabetes clinic and home blood glucose concentrations. BMF 1992;305:1194-6. (14 November.)

2 Johnson RN, Metcalf PA, Baker JR. Fructosamine: a new approach to the estimation of serum glycosyl protein. An index of diabetic control. Clin Chem Acta 1983;127:87-95.

EDITOR,-It is interesting that although Lesley V Campbell and colleagues performed their study on patients with non-insulin dependent diabetes mellitus, 21 of the 34 patients who had a disparity between their home and clinic blood glucose readings were in fact receiving insulin.' Such patients may have very little $B$ cell function left and may therefore have random fluctuations in blood

glucose concentrations, as in insulin dependent diabetes mellitus.

If the 15 patients who had errors in their monitoring technique are excluded there are 19 remaining patients who had a disparity between their blood glucose concentrations, out of a total of $283(6.7 \%)$ - that is marginally higher than can happen by chance $(5 \%)$, but it could well be due to the stress of travelling and waiting in the clinic.

Finally, the technique used to estimate blood glucose concentration is important, ${ }^{2}$ and some difference in results would be expected if a different technique was used by patients at home and in the clinic.

JS GUJRAL PG MCNALLY A C BURDEN

Diabetes Research, Leicester General Hospital, Leicester LE5 4PW

1 Campbell LV, Ashwell SM, Borkman M, Chisholm DJ. White coat hyperglycaemia: disparity between diabetes clinic and home blood glucose concentrations. BMF 1992;305:1194-6. (14 November.)

2 Marks V, Rose SC. Hypoglycaemia. Oxford: Blackwell Scientific, 1981:411-8.

AUTHOR'S REPLY,-Our paper dealt with a topic on which most diabetes specialists have strong feelings but few studies provide objective data. While it is possible, as $\mathrm{H} \mathrm{J}$ Bodansky suggests, to double the patients' visits to hospital or their general practice, we prefer to avoid non-essential visits, knowing that patients' time (like ours) is precious. We now have an "immediate" fructosamine service, similar to that discussed by Carol Sullivan and colleagues. Our patients do not seem to regard the clinic measurement of blood glucose concentration as demeaning: one sample is used for measurement of both blood glucose and glycated protein concentrations. We have an appointment system preventing queues.

As (anecdotally) it seems that self monitoring of blood glucose concentration is more unreliable in Britain than we found in our falsification study could this be due to poor instruction of patients; the self monitoring technique not being reevaluated in elderly people; community or social resources not being used if the patient is incapable of testing; or patients' fear of doctors making falsification more likely?

We agree that the haemoglobin $A_{1 c}$ (or fructosamine) concentration is the only objective measurement, but it will reassure the doctor and patient only if the diabetes is well controlled. If the diabetes is not well controlled how do they adjust treatment with reasonable safety without data from self monitoring?

J S Gujral and colleagues suggest that patients' blood glucose concentrations may fluctuate randomly and that the discrepancies may be largely due to chance. As stated in our paper, however, subjects were selected only if they had a large discrepancy between readings at at least two consecutive clinic visits (which would occur by chance only $0.25 \%$ of the time at most). We also stated, as they do, that the cause of discrepancy in those without errors of technique could be the stress of the visit but point out that further investigation is required.

In reply to Gujral and colleagues' final point, when errors of technique have been eliminated only a small discrepancy can be attributed to differences in the method of testing. Clearly, a discrepancy of at least $5 \mathrm{mmol} / \mathrm{l}$ quoted in our paper could not be predominantly due to differences in the methods used by the patients and clinic.

Diabetes Centre, St Vincent's Hospital

LESLEY CAMPBELI

Darlinghurst, NSW 2010

Australia

1 Campbell LV, Reinhardt J, Ashwell S, McLay J. Verification of blood glucose recording during outpatient stabilisation of diabetes. Diabetes 1991;40:140.

\section{Nurse triage}

EdITOR,-Tom Keighley and Jan Maycock favour nurse triage to address the patient's charter's standard on immediate assessment of patients attending accident and emergency departments. However, they fail to distinguish research from anecdote, and they have misquoted or misunderstood several of the papers that they cite as evidence. Of the 11 references quoted, one is the patient's charter, one our own study of nurse triage, ${ }^{2}$ criticisms of which we have answered, ${ }^{3}$ and a third an observational before and after study that was flawed methodologically.5 The others are anecdotes.

Keighley and Maycock quote Nuttall as saying "that a system of nurse triage can significantly reduce waiting times when performed effectively." Nuttall, however, provides only a description of the triage process at one hospital in Australia and does not examine the effect of triage on waiting times. [See correction, p 160.]

They quote Slater as showing that the provision of separate triage nurses for ambulant and seriously ill patients "halves the waiting times for acutely ill patients." Again, this paper is anecdotal, and the only relevant passage reads: "We have not done studies to show whether patients' average time in clinic is shorter than it was before the change, but the staff believe that it is."

They go on to quote Shields's suggestion that ambulant patients should be seen in a separate area from acutely ill patients and her conclusion that this halved treatment delays. ${ }^{8}$ They do not mention that the shortening of delay benefited the least urgent patients, who were awarded a treatment area and a physician to themselves, and who in Britain would likely have been seen by a general practitioner. In particular, they do not quote Shields's statement that "Unfortunately, there was little or no time change for the care of categories I and II (more urgent) patients."

What is the objective of nurse triage? Is it to ensure that those in most urgent need of care receive it first, or is it to act as a public relations exercise for those patients who could do without attending the accident and emergency department at all? If the former, patients with minor symptoms would wait longest; if the latter, they would be awarded priority. In Shields's study the provision of a separate primary care doctor satisfied the latter objective but did nothing for the former.

Of these papers, we would claim that ours alone meets the criteria of being well structured, valid, and reliable. Our results do not support Keighley and Maycock's conclusions.

STEVE GEORGE

Wessex Institute of Public Health,

University of Southampton Medical School, Southampton SO9 5NH

SUSAN READ BRIAN WTLLIAMS

Medical Care Research Unit,

University of Sheffield Medical School,

Sheffield S10 2RX

1 Keighley T, Maycock J. The patient's charter and the triag nurse. BMY 1992;305:1310. (28 November.)

2 George SL, Read S, Westlake L, Williams BT, Fraser-Moodie A Pritty P. Evaluation of nurse triage in a British accident and emergency department. BMF 1992;304:876-8.

3 George SL, Westlake L, Read S, Williams BT, Fraser-Moodie A, Pritty $P$. Nurse triage in accident and emergency departments. BMF 1992:304:1379.

4 Mallett J, Woolwich C. Triage in accident and emergency departments. F Adv Nursing 1990;15:1443-51.

5 George SL, Westlake L, Read S, Williams BT. Janforum feedback-debate about triage in accident and emergency departments (critique). I Adv Nursing 1991;16:1391.

departments (critique). $f$ Adv Nursing 1991;16:1391.
Nuttall M. The chaos controller. Nursing Times 1982;20:656-8.

7 Slater R. Triage nurses in the emergency department. Am Slater R. Triage nurses in
Nursing 1970;70:127-9.

8 Shields JE. Making triage work-the experience of an urban emergency department. $f$ Emerg Nursing 1976;2:37-41.

EdIToR,-Tom Keighley and Jan Maycock's editorial shows the confusion that surrounds the 